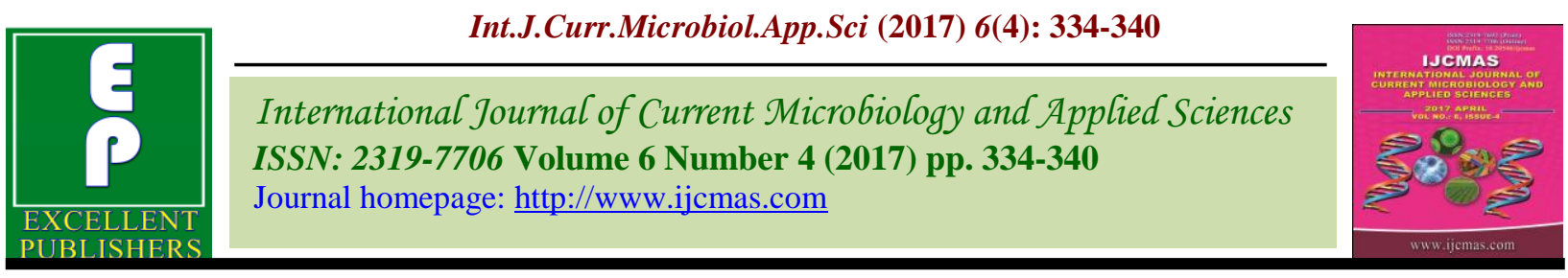

Original Research Article

https://doi.org/10.20546/ijcmas.2017.604.036

\title{
Antifungal Activity of Biogenic Platinum Nanoparticles: An in vitro Study
}

\author{
Kapil Dev Sharma* \\ Research Scholar, Shri JJT University, Jhunjhunu, Rajasthan 333001, India \\ *Corresponding author
}

\begin{tabular}{|c|c|}
\hline & $\mathbf{B} \mathbf{S} \mathbf{T} \mathbf{R} \mathbf{C} \mathbf{T}$ \\
\hline Keywords & \multirow{4}{*}{$\begin{array}{l}\text { The aim of this study was to screen biogenic platinum nanoparticles for antifungal } \\
\text { properties by a combination of in vitro methods. During this study, marine actinobacteria } \\
\text { (Streptomyces sp. mediated biogenic platinum nanoparticles were screened for their } \\
\text { antifungal activity against Aspergillus flavus, A. niger, Penicillium sp., Candida albicans } \\
\text { and } C \text {. tropicalis. Biologically synthesized platinum nanoparticles exhibited broad } \\
\text { spectrum antifungal activity against test organisms. Particles exhibited high activity } \\
\text { against yeast viz, Candida albicans }(16.66 \pm 1.52) \text { and } C \text {. tropicalis }(18.33 \pm 1.52) \text {, while } \\
\text { moderate antifungal activity against molde viz, A. flavus (11.00 } \pm 1.00) \text {, A. niger } \\
(09.33 \pm 1.52) \text {, Penicillium sp. (06.00 } \pm 1.00) \text {. These particles exhibited antifungal activity } \\
\text { with minimum inhibitory concentration ranging from } 10-40 \mu \mathrm{g} / \mathrm{ml} \text {. }\end{array}$} \\
\hline $\begin{array}{l}\text { Biogenic, Platinum } \\
\text { nanoparticles, } \\
\text { Antifungal. }\end{array}$ & \\
\hline Article Info & \\
\hline $\begin{array}{l}\text { Accepted: } \\
02 \text { March } 2017 \\
\text { Available Online: } \\
10 \text { April } 2017\end{array}$ & \\
\hline
\end{tabular}

\section{Introduction}

Fungi are very important group of microorganisms with maximum number of representatives. Fungi provide several direct or indirect benefits to mankind such as decomposition of organic material, bioremediations of toxic materials, production of antibiotics and other industrial products etc (Rani et al., 2014; Kawaguchi et al., 2013; Sunna et al., 1997). In contrast to the benefits, fungi can also leads a variety of diseases in plants, humans and animals. Fungal infection such as, Aspergillosis, Candidiasis and Mucormycosis etc. pose a significant negative impact on human health, most of the fungi produces slow and long term infection in human body and is quite difficult to eliminate. Development of drug resistance in pathogenic strains is an important virulence factor of fungi, therefore there is a constant need to develop newer products with antifungal potential (Vanden et al., 1997). Nanotechnology is a science that deals with the synthesis, development, manipulation and applications of tinny molecules that measure 100 nanometers or less. Due to their very small size, they carry unique properties and can be utilize for the development of new products. Most recently, there is a global interest among the scientists to develop, improve, employ and use nanoparticles for solving various problems encountered by mankind. In recent past, a variety of metallic and non-metallic nanoparticles are extensively used in various fields such as pharmaceuticals, optical devices, catalyst, bioremediation, electronic and sensor technology (Praetorius et al., 2007; Karthik et al., 2013; Anderson et al., 2006; Jiang et al., 2005; Agarwal et al., 2014; Sharpe et al., 2014). 
Various nanoparticles viz. silver, gold, zinc oxide, platinum are being excessively used in several industries such as food, pharmaceutical and bioelectronics. Among them platinum nanoparticle is one of the rare and very useful variety of nanoparticle. In recent past, platinum nanoparticles have been reported to exhibit great antioxidant properties. Platinum nanoparticles are also being used for coating materials, and for the development of nanofibers and polymer membranes.

These particles are also reported to have great applications in the development of fuel cells and hydrogen storage materials (Wen et al., 2008; Li et al., 2007). In recent past nanoparticles have been reported to exhibit significant antimicrobial activity (Ahmed et al., 2016; Elhusseiny et al., 2013), however the reports on antifungal activity remains limited. Therefore, this study is designed to screen the platinum nanoparticles for their properties to inhibit the growth of fungi.

\section{Materials and Methods}

Platinum nanoparticles were previous biologically synthesized using marine actinobacteria Streptomyces sp. isolated from soil sediments samples collected from coastal areas of Chennai, India, while Chloroplatinic acid hexahydrate was used as substrate. These nanoparticles were characterize using, UVvisible spectrophotometer, FTIR Spectroscopy, XRD and TEM analysis (Data not shown).

\section{Antifungal activity of the platinum nanoparticles}

\section{Test organisms}

Aspergillus flavus, A. niger, Penicillium sp., Candida albicans and $C$. tropicalis were used for studying the antifungal activity of biogenic platinum nanoparticles. All fungal cultures were maintained on potato dextrose agar medium and stored at $4{ }^{\circ} \mathrm{C}$.

\section{Antibiogram}

All the clinical isolates of fungi were screened for their sensitivity towards standard antibiotics by disc diffusion method. Antibiotics included Miconazole $(10 \mu \mathrm{g} /$ disc $)$, Clotrimazole (10 $\mu \mathrm{g} / \mathrm{disc})$, Ketoconazole (10 $\mu \mathrm{g} /$ disc $)$, Amphotericin -B (20 $\mu \mathrm{g} /$ disc) and

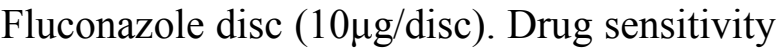
test was performed by disc diffusion method on Potato dextrose agar plates. Fungal isolates were inoculated in to potato dextrose broth for 8 hours. Isolates were seeded on potato dextrose agar plates by using sterilize cotton swabs. The standard antibiotic discs were placed on the agar surface using a sterilize forceps. Plates were incubated at $28^{\circ} \mathrm{C}$ for 48 72 hours. Plates were observed for zone of inhibition. The experiment was performed in triplicates (Perez et al., 1990).

\section{Antifungal activity}

Antifungal activity of the biologically synthesized platinum nanoparticles was checked by agar well diffusion method on Potato dextrose agar plates. The fungal cultures were lawn cultured on potato dextrose agar plates by using sterilised cotton swabs. In each of these plates, three wells were cut out using a standard cork borer ( 7 $\mathrm{mm}$ diameter). Using a micropipette, $100 \mu \mathrm{l}$ of Chloroplatinic acid hexahydrate solution $(100 \mu \mathrm{g} / \mathrm{ml}), 100 \mu \mathrm{l}$ of platinum nanoparticle $(100 \mu \mathrm{g} / \mathrm{ml})$ and $100 \mu \mathrm{l}$ of distilled water was added to separate wells. Plates were incubated for $48-72$ hours at $28^{\circ} \mathrm{C}$. Anti-fungal activity was evaluated by measuring the zone of inhibition (Kumar et al., 2010). Experiment was performed in triplicates. 


\section{Determination of relative percentage inhibition}

The relative percentage inhibition of the biologically synthesized platinum nanoparticles with respect to positive control was calculated by using the following formula (Kumar et al., 2010).

Relative percentage inhibition of the biologically synthesized platinum nanoparticles $=$

$[100 \times(\mathbf{x}-\mathbf{y})] /(\mathbf{z}-\mathbf{y})$

Where,

x: total area of inhibition of the biologically synthesized platinum nanoparticles

y: total area of inhibition of the solvent

z: total area of inhibition of the standard drug

The total area of the inhibition was calculated by using area $=\pi r^{2}$; where, $r=$ radius of zone of inhibition.

\section{Determination of minimum inhibitory concentration (MIC)}

MIC of the biologically synthesized platinum nanoparticles was performed by modified agar well diffusion method. Sample was diluted in sterilized distilled water to make a concentration range from $1-1000 \mu \mathrm{g} / \mathrm{ml}$. Test cultures were inoculated in PDB and seeded on PDA plates using sterilized cotton swabs. In each of these plates four wells were cut out using a standard cork borer $(7 \mathrm{~mm})$. Using a micropipette, $100 \mu \mathrm{l}$ of each dilution was added in to wells. Plates were incubated at $28^{\circ} \mathrm{C}$ for 72 the results were recorded. The minimum concentration of each extract showing a clear zone of inhibition was considered to be MIC (Rios et al., 1988; Okunji et al., 1990).

\section{Statistical analysis}

The results of the antifungal activity of biologically synthesized platinum nanoparticles are expressed as mean \pm standard deviation of the response of 3 replicates determinations per sample. Results were analyzed by using Microsoft Excel 2007.

\section{Results and Discussion}

Platinum is a very rare and one of the most costly metal available on earth. It's highly resistance to corrosion and is the least reactive metal therefore used widely for specific applications. Platinum is being widely used in nanotechnology and can be reduced to nanoparticles by various physical, chemical and biological processes. These nanoparticles can exhibit unique properties depending upon the method used for the production of particles and their size.

In recent past, platinum nanoparticles has been reported to exhibit several pharmaceutical properties such as antioxidant activity, anticancer activity (Borse et al., 2015) and antimicrobial activity (Rajathi et al., 2014).

In a study, pectin and sodium borohydride synthesized platinum nanoparticles exhibited significant antibacterial activity against Escherichia coli and Aeromonas hydrophila. In another study, phytofabricated platinum nanoparticles exhibit strong antibacterial activity toward Vibrio cholera, Staphylococcus aureus, Streptococcus pyogens, Salmonella typhi and E. coli. During this study the biologically synthesized platinum nanoparticles were screened for their antifungal activity by using various in vitro methods.

\section{Antibiogram study}

Antibiogram studies performed against fungal isolates provide systemic information about the drug resistant pattern of the test cultures against commonly used antibiotics. 
Table.1 Antibiogram study of fungal isolates

\begin{tabular}{llllll}
\hline \multirow{2}{*}{ Test organisms } & \multicolumn{3}{l}{ Antibiotics used } & & \\
\cline { 2 - 6 } & Miz & Ctz & Kt & Ap & Fu \\
\hline A. flavus & $\mathrm{S}$ & $\mathrm{R}$ & $\mathrm{S}$ & $\mathrm{S}$ & $\mathrm{S}$ \\
A. niger & $\mathrm{R}$ & $\mathrm{S}$ & $\mathrm{S}$ & $\mathrm{S}$ & $\mathrm{S}$ \\
Penicillium sp. & $\mathrm{R}$ & $\mathrm{S}$ & $\mathrm{S}$ & $\mathrm{S}$ & $\mathrm{S}$ \\
C. albicans & $\mathrm{S}$ & $\mathrm{I}$ & $\mathrm{I}$ & $\mathrm{I}$ & $\mathrm{S}$ \\
C. tropicalis & $\mathrm{S}$ & $\mathrm{S}$ & $\mathrm{S}$ & $\mathrm{S}$ & $\mathrm{S}$ \\
\hline
\end{tabular}

S: Sensitive, I: Intermediate, R: Resistant, n.a.: not applied, Miz: Miconazole $(10 \mu \mathrm{g} / \mathrm{disc})$, Ctz: Clotrimazole $(10 \mu \mathrm{g} / \mathrm{disc})$, Ketoconazole $(10 \mu \mathrm{g} / \mathrm{disc}), \mathrm{Ap}$ :

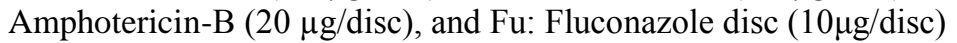

Table.2 Antifungal activity of biologically synthesize platinum nanoparticles

\begin{tabular}{llll}
\hline Test organism & \multicolumn{3}{l}{ Zone of inhibition $(\mathbf{m m})$} \\
\cline { 2 - 4 } & Pt NPs & PC & NC \\
\hline Aspergillus flavus & $11.00 \pm 1.00$ & $17.33 \pm 2.08$ & $0.0 \pm 0.0$ \\
Aspergillus niger & $09.33 \pm 1.52$ & $16.00 \pm 3.00$ & $0.0 \pm 0.0$ \\
Penicillium sp. & $06.00 \pm 1.00$ & $15.66 \pm 1.52$ & $0.0 \pm 0.0$ \\
Candida albicans & $16.66 \pm 1.52$ & $19.33 \pm 1.52$ & $0.0 \pm 0.0$ \\
Candida tropicalis & $18.33 \pm 1.52$ & $23.00 \pm 1.73$ & $0.0 \pm 0.0$ \\
\hline
\end{tabular}

Here, PC: positive control, NC: negative control

Values are expressed as mean \pm standard deviation of the three replicates,

Zone of inhibition not include the diameter of the well.

Table.3 Relative percentage inhibitions of biologically synthesize platinum nanoparticles

\begin{tabular}{ll}
\hline Test organism & RPI (\%) \\
\hline Aspergillus flavus & 40.27 \\
Aspergillus niger & 34.02 \\
Penicillium sp. & 14.66 \\
Candida albicans & 74.31 \\
Candida tropicalis & 63.53 \\
\hline
\end{tabular}

RPI: Relative percentage inhibition

Table.4 Minimum inhibitory concentrations of biologically synthesize platinum nanoparticles

\begin{tabular}{ll}
\hline Test organism & MIC $(\boldsymbol{\mu g} / \mathbf{m l})$ \\
\hline Aspergillus flavus & 20 \\
Aspergillus niger & 40 \\
Penicillium sp. & 20 \\
Candida albicans & 10 \\
Candida tropicalis & 10 \\
\hline MIC: Minimum inhibitory concentration &
\end{tabular}

During this study, Aspergillus flavus, A. niger, Penicillium sp., Candida albicans and $C$. tropicalis were subjected to antibiogram study against antifungal drugs such as miconazole, 
clotrimazole, ketoconazole, amphotericin-B and fluconazole disc. Results represents that almost all the fungal cultures were sensitive towards the tested antibiotics, however $A$. flavus exhibited resistance towards clotrimazole, while A. niger and Penicillium sp. resist miconazole. Results of antibiogram study are summarized in Table 1.

\section{Antifungal activity of biologically synthesize platinum nanoparticles}

In this study, biologically synthesize platinum nanoparticles was screened for antifungal activity against Aspergillus flavus, A. niger, Penicillium sp., Candida albicans and $C$. tropicalis. Biologically synthesized platinum nanoparticles exhibited high antifungal activity, while highest antibacterial activity was shown against $C$. tropicalis $(18.33 \pm 1.52)$, followed by $C$. albicans (16.66 \pm 1.52$), A$. flavus (11.00 \pm 1.00$)$, A. niger $(09.33 \pm 1.52)$ and Penicillium sp. $(06.00 \pm 1.00)$. Results of antifungal activity of biologically synthesize platinum nanoparticles are summarized in Table 2.

\section{Relative percentage inhibition}

During this study, antifungal activity of biologically synthesize platinum nanoparticles was compared with the antifungal activity of standard drugs for evaluating relative percentage inhibition. The biologically synthesize platinum nanoparticles exhibited maximum relative percentage inhibition against $C$. albicans (74.31\%), followed by $C$. tropicalis (63.53\%), A. flavus (40.27\%), A. niger $(34.02 \%)$ and Penicillium sp. (14.66\%). Results of relative percentage inhibition are summarized in Table 3.

\section{Minimum inhibitory concentration}

Minimum inhibitory concentration values of the biologically synthesize platinum nanoparticles against fungal strains were range between 10-40 $\mu \mathrm{g} / \mathrm{ml}$. The biologically synthesize platinum nanoparticles exhibited minimum inhibitory concentration against $C$. albicans $(10 \mu \mathrm{g} / \mathrm{ml})$, C. tropicalis $(10 \mu \mathrm{g} / \mathrm{ml})$, followed by A. flavus $(20 \mu \mathrm{g} / \mathrm{ml})$, Penicillium sp. $(20 \mu \mathrm{g} / \mathrm{ml})$ and A. niger $(40 \mu \mathrm{g} / \mathrm{ml})$. Results of MIC values of the biologically synthesize platinum nanoparticles are summarized in Table 4.

During this work, actinobacteria mediated biogenic platinum nanoparticles were evaluated for its antifungal property. These particles exhibited a significant antifungal activity against a broad range of fungi including $C$. albicans, followed by $C$. tropicalis, A. flavus, A. niger and Penicillium sp. It could be concluded that marine actinobacteria can effectively produce platinum nanoparticles with broad spectrum antifungal properties.

\section{Acknowledgement}

Authors wish to thank management of Shri JJT University, Jhunjhunu, Rajasthan, India, for providing necessary facilities and support for the completion of this work.

\section{References}

Agarwal, A., Mehra, A., Karthik, L., Kumar, G., Rao, K.V.B. 2014. Antibiofouling property of marine actinobacteria and its mediated nanoparticle. Int. $J$. Nanoparticles, 7: 294-306.

Ahmed, K.B., Raman, T., Anbazhagan, V. 2016. Platinum nanoparticles inhibit bacteria proliferation and rescue zebrafish from bacterial infection. $R S C$ Adv., 6: 44415-44424.

Anderson, D.J., Moskovits, M. 2006. A SERS-active system based on silver nanoparticles tethered to a deposited silver film. The J. Physical Chem. B., 
110: 13722-13727.

Borse, V., Kaler, A., Banerjee, U.C. 2015. Microbial synthesis of platinum nanoparticles and evaluation of their anticancer activity. Int. J. Emerging Trends in Electrical and Electronics, 11: 26-31.

Elhusseiny, A.F., Hassan, H.H. 2013. Antimicrobial and antitumor activity of platinum and palladium complexes of novel spherical aramides nanoparticles containing flexibilizing linkages: structure-property relationship. Spectrochimica Acta Part A: Mol. Biomol. Spectroscopy, 103: 232-245.

Jiang, Z.J., Liu, C.Y., Sun, L.W. 2005. Catalytic properties of silver nanoparticles supported on silica spheres. The J. Physical Chem. B., 109: 1730-1735.

Karthik, L., Kumar, G., Keswani, T., Bhattacharyya, A., Palakshi Reddy, B., Rao, K.V.B. 2013. Marine actinobacterial mediated gold nanoparticles synthesis and their antimalarial activity. Nanomed., 9: 95160.

Kawaguchi, M., Nonaka, K., Masuma, R., Tomoda, H. 2013. New method for isolating antibiotic-producing fungi. The J. Antibiotics, 66: 17-21.

Kim, J., Takahashi, M., Shimizu, T., Shirasawa, T., Kajita, M., Kanayama, A., Miyamoto, Y. 2008. Effects of a potent antioxidant, platinum nanoparticle, on the lifespan of Caenorhabditis elegans. Mechanisms of Ageing and Development, 129(6): 32231.

Rani, B., Kumar, V., Singh, J., Bisht, S., Teotia, P., Sharma, S., Kela, R. 2014. Bioremediation of dyes by fungi isolated from contaminated dye effluent sites for bio-usability. Brazilian J. Microbiol., 45: 10551063.
Kumar, G., Karthik, L., Rao, K.B. 2010. Phytochemical composition and in vitro antimicrobial activity of Bauhinia racemosa Lamk (Caesalpiniaceae). Int. J. Pharmaceutical Sci. Res., 1: 51-58.

Kumar, G., Karthik, L., Rao, K.V.B. 2010. In vitro anti-Candida activity of Calotropis gigantea against clinical isolates of Candida. J. Pharmacy Res., 3: 539-542.

Li, Y., Yang, R.T., Liu, C.J., Wang, Z. 2007. Hydrogen storage on carbon doped with platinum nanoparticles using plasma reduction. Industrial and Engi. Chem. Res., 46: 8277-8281.

Okunji, C.O., Okeke, C.N., Gugnani, H.C., Iwu, M.M. 1990. An antifungal saponin from fruit pulp of Dracaena mannii. Int. J. Crude Drug Res., 28: 193-199.

Perez, C., Pauli, M., Bazerque, P. An antibiotic assay by the agar well diffusion method. Acta Biol. Med. Exp., 15: 113-115.

Praetorius, N.P., Mandal, T.K. 2007. Engineered nanoparticles in cancer therapy. Recent Patents on Drug Delivery and Formulation, 1: 37-51.

Priyaragini, S., Veena, S., Swetha, D., Karthik, L., Kumar, G., Rao, K.V.B. 2014. Evaluating the effectiveness of marine actinobacterial extract and its mediated titanium dioxide nanoparticle in the degradation of azo dyes. $J$. Environ. Sci., 26: 775-782.

Rajathi, F.A.A., Nambaru, V.R.M.S. 2014. Phytofabrication of nano-crystalline platinum particles by leaves of Cerbera manghas and its antibacterial efficacy. Int. J. Pharma and Bio Sci., 5: 619-628.

Rao, C.N.R., Kulkarni, G.U., Thomas, P.J., Edwards, P.P. 2000. Metal nanoparticles and their assemblies. Chem. Society Reviews, 29: 27-35.

Rios, J.L., Recio, M.C., Vilar, A. 1988. Screening methods for natural products with antimicrobial activity: A 
review of literature. J. Lozano-Chiu, M., Rex, J.H., Sanglard, Ethnopharmacol., 23: 127-149. $\quad$ D. 1997. Antifungal drug resistance in Sharpe, E., Andreescu, S. 2015. Portable pathogenic fungi. Med. Mycol., 36: nanoparticle based sensors for antioxidant analysis. Methods in Mol. Biol., 1208: 221-31.

Sunna, A., Antranikian, G. 1997. Xylanolytic enzymes from fungi and bacteria. Critical Rev. Biotechnol., 17: 39-67. 119-128.

Wen, Z., Liu, j., Li, J. 2008. Core/shell Pt/C nanoparticles embedded in mesoporous carbon as a methanoltolerant cathode catalyst in direct methanol fuel cells. Advanced Materials, 20:743-747.

Vanden, B.H., Dromer, F., Improvisi, I., How to cite this article:

Kapil Dev Sharma. 2017. Antifungal Activity of Biogenic Platinum Nanoparticles: An in vitro study. Int.J.Curr.Microbiol.App.Sci. 6(4): 334-340.

doi: https://doi.org/10.20546/ijcmas.2017.604.036 